\title{
Integration of Fullerenes as Electron Acceptors in 3D Graphene Networks: Enhanced Charge Transfer and Stability through Molecular Design
}

Maira R. Cerón, ${ }^{\mathrm{a} *}$ Cheng Zhan, ${ }^{\mathrm{a}}$ Patrick G. Campbell, ${ }^{\mathrm{a}}$ Megan Freyman, ${ }^{\mathrm{a}}$ Christy Santoyo, ${ }^{\mathrm{b}}$ Luis Echegoyen, ${ }^{\mathrm{b}}$ Brandon C. Wood, ${ }^{\mathrm{a}}$ Juergen Biener, ${ }^{\mathrm{a}}$ Tuan Anh Pham, ${ }^{\mathrm{a}}$ and Monika M. Biener. ${ }^{\mathrm{a} *}$

a Materials Science Division, Lawrence Livermore National Laboratory, 7000 East Ave, Livermore, CA 94550, United States. *Dr. M. R. Cerón ceronhernand1@1lnl.gov, *Dr. M. M. Biener biener3@1lnl.gov

b Department of Chemistry, University of Texas at El Paso, $500 \mathrm{~W}$ University Ave, El Paso, TX 79968, United States.

\section{General Procedures}

All chemicals were reagent grade, purchased from Sigma Aldrich. Carbon Fullerene C60 (99.0\% purity) and graphene oxide (GO, 1-2 layer, 300-800 nm diameter sheets) were purchased from CheapTubes.

MALDI-TOF mass spectrometric measurements were conducted on a Bruker Microflex LRF mass spectrometer on reflector positive mode. The NMR spectra were recorded using a JEOL $600 \mathrm{MHz}$ spectrometer. Thermogravimetric analysis (TGA) was carried out using a Mettler Toledo TGA/DSC 3+ (SF/1100). The sample was placed in a Pt crucible with lid, hold for 90 min at 35 ${ }^{\circ} \mathrm{C}$ and heated up to $1050{ }^{\circ} \mathrm{C}$ with a ramping rate of $5{ }^{\circ} \mathrm{C} / \mathrm{min}$ under $\mathrm{N}_{2}$ atmosphere. A blank with an empty crucible was run before each experiment to remove the background. Cyclic voltammetry (CV) was conducted in a glovebox under argon at room temperature using a Bio-Logic Potentiostat. The scan rate for $\mathrm{CV}$ experiments was $5 \mathrm{mV} / \mathrm{s}$. A one compartment cell with a standard three-electrode set up was used, consisting of a disk-shaped GMA as the working electrode, a platinum wire as the counter electrode and a silver-silver nitrate reference electrode, in a solution of anhydrous acetonitrile containing $0.1 \mathrm{M}$ tetrabutylammonium perchlorate (TBAP).

\section{Synthesis of 3D Mesoporous Graphene Macro-Assemblies}

$6 \mathrm{~mm}$ diameter and $250 \mu \mathrm{m}$ thick disk-shaped GMAs were synthesized through base-catalyzed organic sol-gel chemistry following the previously reported procedure. ${ }^{[1]}$ Graphene oxide was used as received and dispersed in Milli-Q water $(20 \mathrm{mg} / \mathrm{mL})$ by ultrasonication during $24 \mathrm{~h}$. Ammonium hydroxide was then added to the suspension $(211 \mu \mathrm{L} / \mathrm{g})$ and the reaction mixture was transferred to discs shaped molds punched into rubber gasket and cured at $80{ }^{\circ} \mathrm{C}$ for 3 days. The resultant monolithic disks were washed with acetone to remove water and supercritical dried. The disks were subsequently carbonized at $1050{ }^{\circ} \mathrm{C}$ during $3 \mathrm{~h}$ under $\mathrm{N}_{2}$ atmosphere. 


\section{Synthesis of Phenyl Amine-[60]Fullerene Monoadduct (PA-C60)}

A mixture of 4'-aminoacetophenone $(1.0 \mathrm{~g}, 3.36 \mathrm{mmol})$ and $p$-toluenesulfonyl hydrazone $(2.2 \mathrm{~g}$, $11.88 \mathrm{mmol})$ in $\mathrm{MeOH}(20 \mathrm{~mL})$ was stirred and refluxed for 2 days. The mixture was left without heating during 1 day and then cooled to $-10 \mathrm{C}$. The white powder was then filtered and washed with cold $\mathrm{MeOH}$ and dichloromethane, dried under vacuum to yield $65 \%$ of product. Diazo addend was prepared in-situ by dissolving 1-(4-aminophenyl)ethano- $p$-toluenesulfonyl hydrazone (122.7 $\mathrm{mg}, 0.208 \mathrm{mmol}$ ) in $1.2 \mathrm{~mL}$ of anhydrous pyridine under $\mathrm{N}_{2}$ atmosphere. $\mathrm{NaOMe}(56.3 \mathrm{mg}, 1.042$ mmol) was added, and the mixture was stirred for $30 \mathrm{~min}$. A solution of $75.0 \mathrm{mg}$ of $\mathrm{C}_{60}(0.1042$ $\mathrm{mmol}$ ) in $7 \mathrm{~mL}$ of anhydrous $o$-DCB was added and stirred at $110{ }^{\circ} \mathrm{C}$ for $6 \mathrm{~h}$. The solvent from the reaction mixture was removed under nitrogen and the crude product was purified by silica gel column chromatography using initially $\mathrm{CS}_{2}$ as eluent to collect the unreacted [60]fullerene, followed by $\mathrm{CS}_{2}: \mathrm{CH}_{2} \mathrm{Cl}_{2}$ 1:1 to collect the monoadduct (PA- $\left.\mathrm{C}_{60}, 41 \%\right)$.

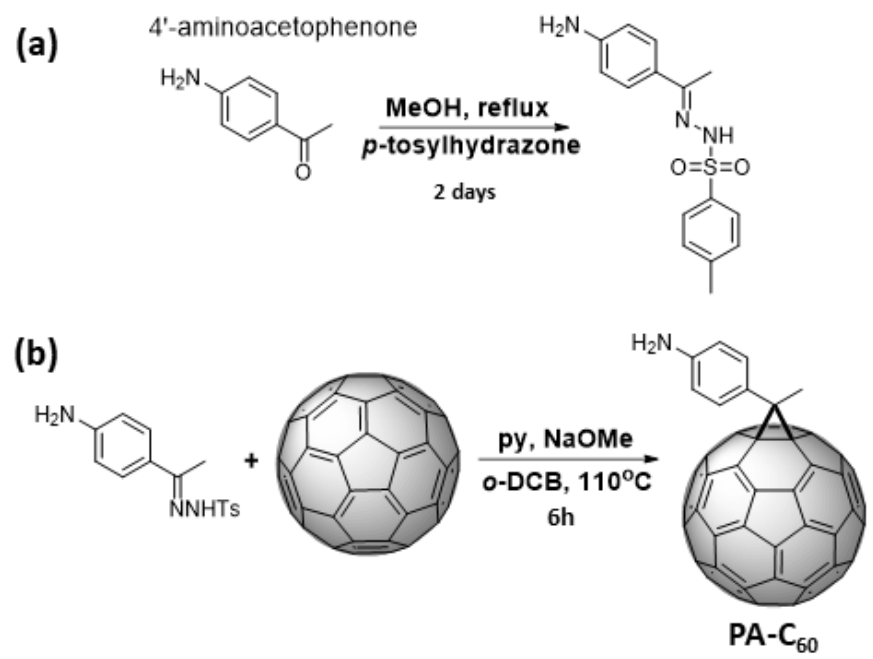

Figure S1. (a) Synthesis of addend. (b) Synthesis of methano derivative PA-C60.

\section{Synthesis of Fullerene-Graphene Networks}

Physisorbed GMA-C 60 and GMA-PA- $\mathrm{C}_{60}$ networks were obtained by submerging $6 \mathrm{~mm}$ diameter, $250 \mu \mathrm{m}$ thick disk-shaped GMAs ${ }^{[1]}$ in $2 \mathrm{mM} \mathrm{CS}_{2}$ solution of $\mathrm{C}_{60}$ or PA- $\mathrm{C}_{60}$, respectively, for $12 \mathrm{~h}$ at room temperature. To exclude the deposition of undispersed (electrochemically inaccessible) fullerene clusters the fullerene solutions were filtered through a $0.02 \mu \mathrm{m}$ pore syringe filter prior to submerging the GMAs. Longer immersion times (up to $24 \mathrm{~h}$ ) resulted in evaporation of the organic solvent in all cases and formation of fullerene clusters due to their low solubility. ${ }^{[2]}$ Increasing the concentration of $\mathrm{C}_{60}$ solutions in which the GMAs were soaked (4 $\mathrm{mM}$ in $\left.\mathrm{CS}_{2}\right)$ also resulted in formation of clusters ${ }^{[3]}$ as observed by scanning electron microscopy (SEM) (Fig. S3); by contrast, no clusters were observed for PA- $\mathrm{C}_{60}$, even when using the higher concentration (4 $\mathrm{mM}$ ) PA-C 60 solution (Fig. S8). Fullerene loadings were determined by measuring the mass difference before and after submerging the GMA in the fullerene solution and were confirmed by 
thermogravimetric analysis (TGA). GMA-fullerene charge transfer properties were assessed by cyclic voltammetry (CV) using a three-electrode setup and a $0.1 \mathrm{M}$ tetrabutylammonium perchlorate (TBAP) electrolyte in acetonitrile.

\section{Computational Details}

Density functional theory (DFT) calculations were carried out with the van der Waals density functional (vdW-DF2), as implemented in the Quantum Espresso package. ${ }^{[4]}$ We utilized ultrasoft pseudopotentials for the description of the interaction between valence electrons and ionic cores. The electronic wave function and charge density were expanded in a plane-wave basis set truncated at the cutoff energy of 30 Ry and 240 Ry, respectively. A 10x10x1 k-point mesh was used to sample the Brillouin zone. For binding energy calculations, we used a graphene substrate modeled by an orthorhombic lattice with 240 carbon atoms with the lattice parameters of $A=25.79 \AA$ and $\mathrm{B}=24.82 \AA$. In addition, to avoid the interaction with periodic images, the length of the supercell in the $z$ direction was chosen as $30.00 \AA$ and $35.53 \AA$ for $\mathrm{C}_{60}$ and PA- $\mathrm{C}_{60}$, respectively. The binding energy of the $\mathrm{C}_{60}\left(\mathbf{P A}-\mathrm{C}_{60}\right)$ molecule and graphene is calculated as:

$$
E_{\text {binding }}=E_{\text {composite }}-E_{C_{60}}-E_{\text {graphene }}
$$

where the $\mathrm{E}_{\text {composite, }} \mathrm{E}_{\mathrm{C} 60}$ and $\mathrm{E}_{\text {graphene }}$ are the total energy of the $\mathrm{C}_{60}$-graphene composite, the isolated $\mathrm{C}_{60}\left(\mathbf{P A}-\mathrm{C}_{60}\right)$ and the graphene from DFT calculations.

Classical simulations of the hybrid systems were carried out with the LAMMPS package ${ }^{[5]}$ in the NVT ensemble at $300 \mathrm{~K}$ using the Nosé-Hoover thermostat. The simulation time was set to be $1000 \mathrm{ps}$ the timestep of $0.001 \mathrm{ps}$. Following a similar work by Neek-Amal et al., ${ }^{[6]}$ Brenner's potential is utilized for the description of $\mathrm{C}-\mathrm{C}$ and $\mathrm{C}-\mathrm{H}$ bonds in $\mathrm{C}_{60}$ and graphene ${ }^{[7]}$ For the interaction between the $\mathrm{C}_{60}$ and graphene, we used the $\mathrm{LJ}$ potential:

$U_{L J}=4 \varepsilon\left\{(\sigma / r)^{12}-(\sigma / r)^{6}\right\}$

with $\sigma=3.4 \AA$ and $\varepsilon=2.4 \mathrm{meV}$ derived from the previous study ${ }^{[8]}$ For the PA-C 60 , since the Brenner's potential for nitrogen is not available, we used the CH's potential for the atom. We also carried out several DFT test calculations to quantify this choice of potential parameter on the binding energy of PA- $\mathrm{C}_{60}$ and graphene. In particular, we found that the replacement of $\mathrm{N}$ by $\mathrm{CH}$ exhibited little impact on the binding energy, yielding a difference of less than $0.03 \mathrm{eV}$. The same $\mathrm{LJ}$ parameters in equation (1) were used to describe the $\pi-\pi$ interaction between benzene ring on ligand and graphene substrate. The $\mathrm{LJ}$ parameter for $\mathrm{CH}_{\mathrm{n}}$-graphene $(\mathrm{n}=1,2,3)$ interaction was set to be $\sigma=3.527 \AA$ and $\varepsilon=2.46 \mathrm{meV}$, following the previous study. ${ }^{[9]}$

\section{Fullerene Charge Transfer Utilization}

The theoretical gravimetric capacity of GMA-fullerene hybrids for one-electron transfer was calculated by multiplying the mol of fullerenes physisorbed in the GMA times the Faraday constant 
divided by the mass of fullerene physisorbed. This is $134.01 \mathrm{C} / \mathrm{g}$ and $114.99 \mathrm{C} / \mathrm{g}$ for GMA-C 60 and GMA-PA-C 60 respectively.

Theo. Utilization $=\frac{\text { mol }_{C_{60}} \times F}{g_{C_{60}}}$

The experimental gravimetric capacity of GMA-fullerene hybrids was calculated by integrating the first charge peak associated with the fullerene in the cyclic voltammograms and subtracting the underlying area of GMA divided by the mass of fullerene physisorbed. This is $89.36 \mathrm{C} / \mathrm{g}$ and 94.75 C/g for GMA-C 60 and GMA-PA- $\mathrm{C}_{60}$ respectively.

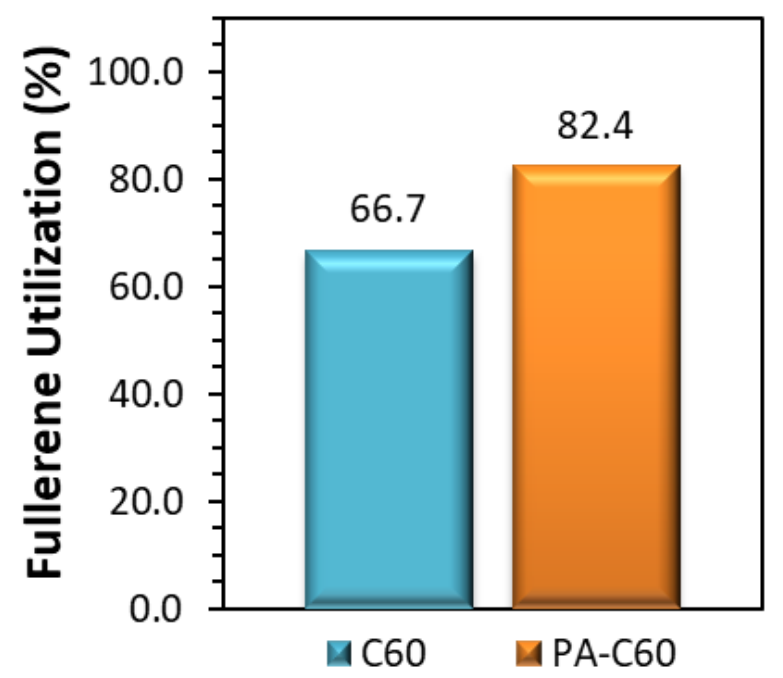

Figure S2. Percentage of fullerene utilization of $\mathrm{GMA}-\mathrm{C}_{60}$ and $\mathrm{GMA}-\mathrm{PA}-\mathrm{C}_{60}$.

\section{Characterization of $\mathrm{C}_{60}$ and PA-C60}
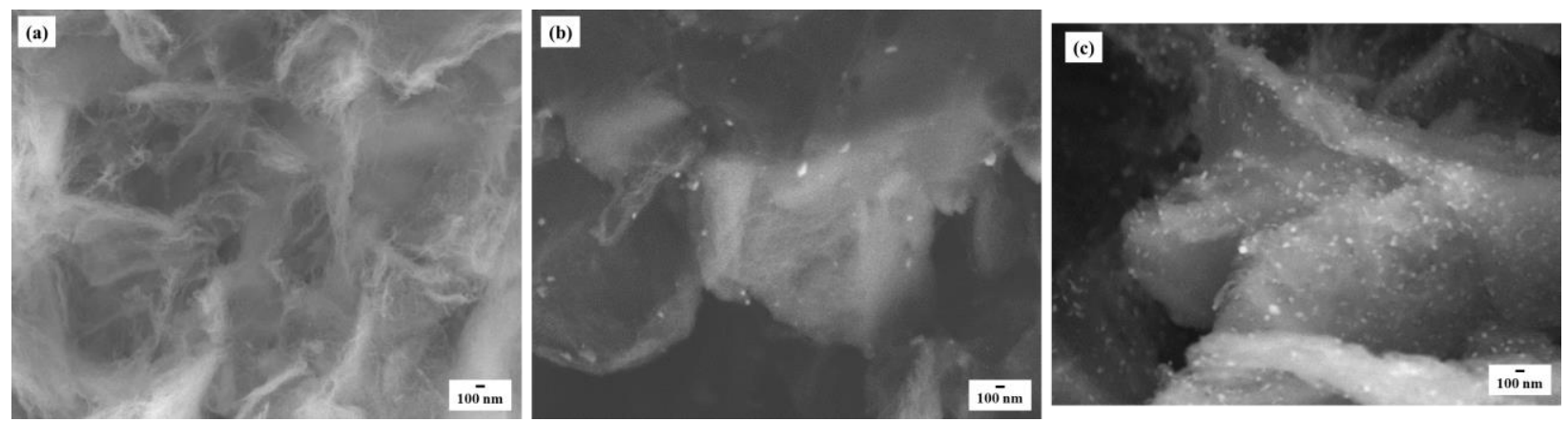

Figure S3. SEM images of GMA-C 60 cross section (a) $2 \mathrm{mM} \mathrm{CS}_{2}$ filtered solution. (b) $6 \mathrm{mM} \mathrm{CS}_{2}$ unfiltered solution. (c) $2 \mathrm{mM}$ Toluene unfiltered solution. 


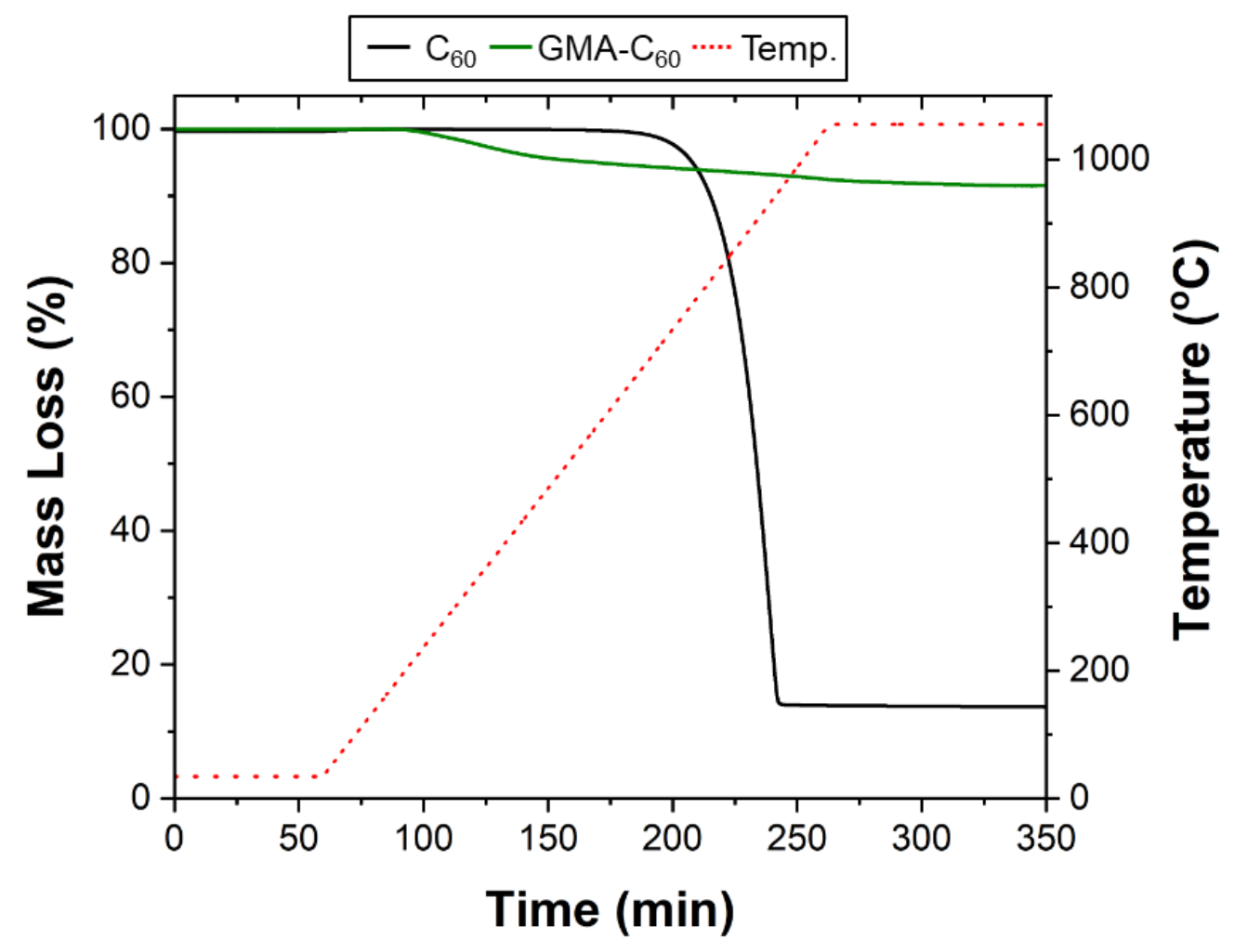

Figure S4. TGA of GMA- $\mathrm{C}_{60}$ (green) and $\mathrm{C}_{60}$ (black) obtained up to $1050{ }^{\circ} \mathrm{C}$, heating rate $5{ }^{\circ} \mathrm{C}$ $\min ^{-1}$ under $\mathrm{N}_{2}$.

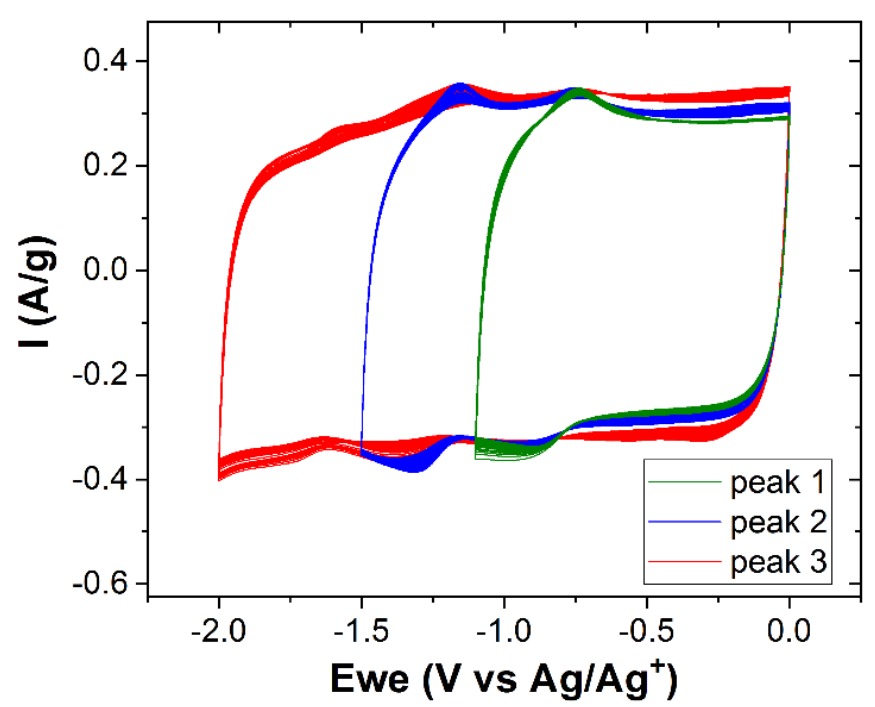

Figure S5. CV of three reduction peaks of GMA-C 60,50 cycles peak 1, 50 cycles peak 2, 50 cycles peak 3, $11.20 \mathrm{wt} \%$ loading, scan rate $5 \mathrm{mV} / \mathrm{s}, 0.1 \mathrm{M}$ TBAP in acetonitrile. 


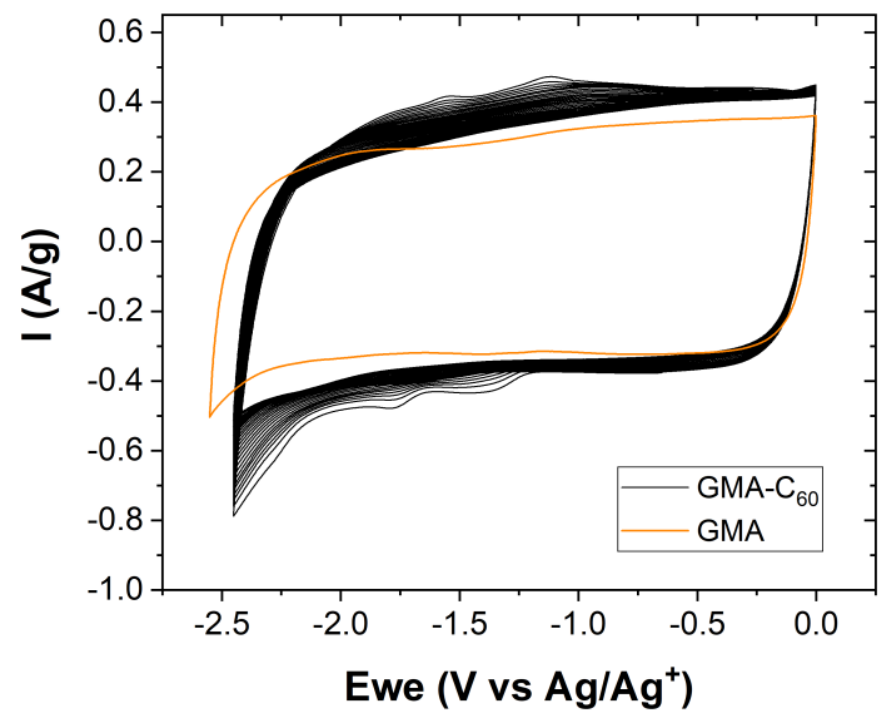

Figure S6. CV of GMA-C 60,200 cycles from 0 to $-2.5 \mathrm{~V}, 10.96 \mathrm{wt} \%$ loading, scan rate $5 \mathrm{mV} / \mathrm{s}$, $0.1 \mathrm{M}$ TBAP in acetonitrile.

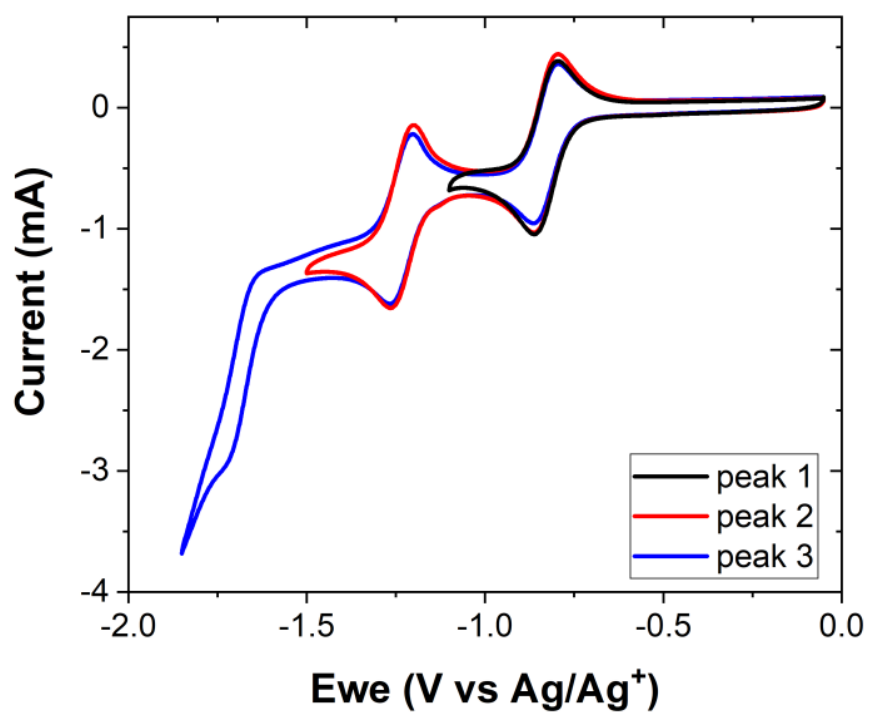

Figure S7. CV of three reduction peaks of $2.5 \mu \mathrm{M} \mathrm{C}_{60}$, scan rate $5 \mathrm{mV} / \mathrm{s}, 0.1 \mathrm{M}$ TBAP in dichloromethane. 

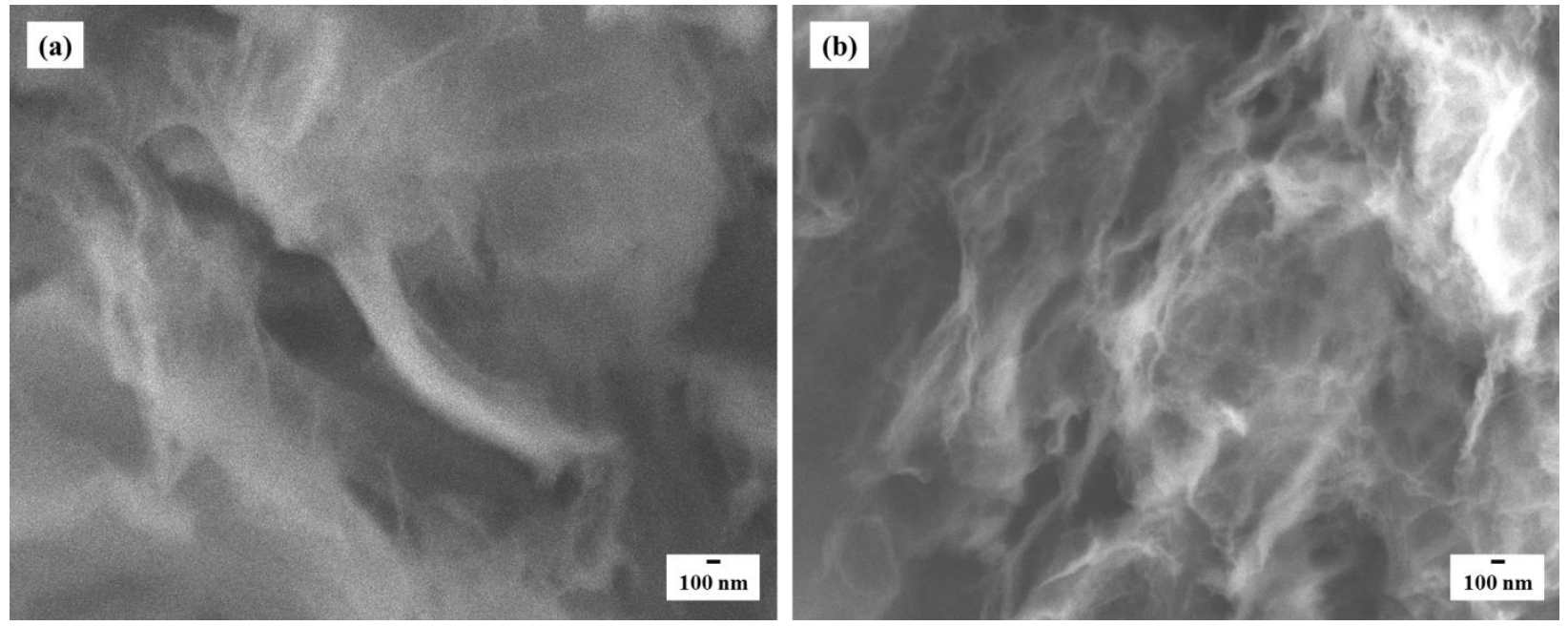

Figure S8. SEM images of GMA-PA-C 60 cross section (a) $2 \mathrm{mM} \mathrm{CS}_{2}$ filtered solution. (b) $4 \mathrm{mM}$ $\mathrm{CS}_{2}$ unfiltered solution.

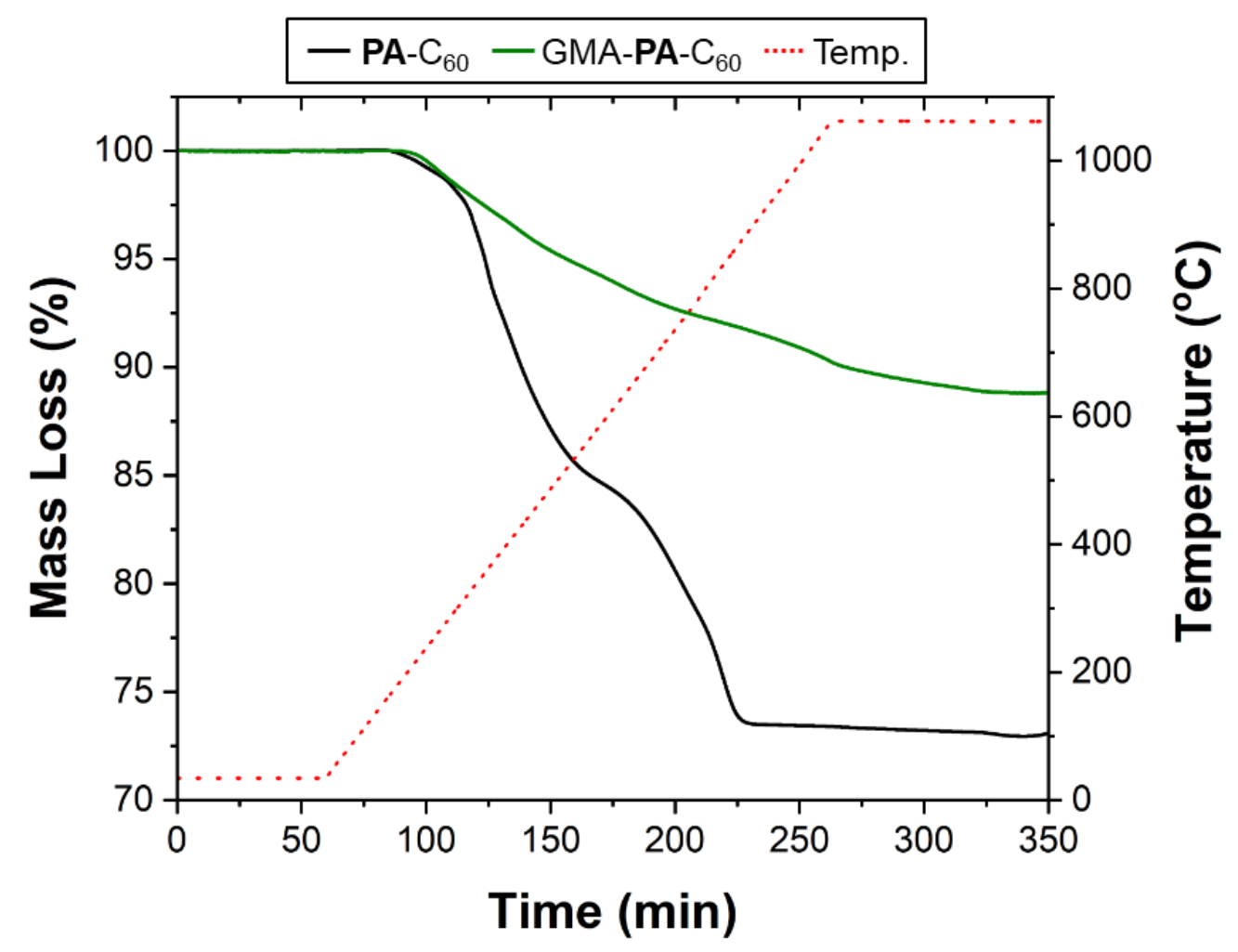

Figure S9. TGA of GMA-PA-C 60 (green) and PA-C 60 (black) obtained up to $1050{ }^{\circ} \mathrm{C}$, heating rate $5{ }^{\circ} \mathrm{C} \min ^{-1}$ under $\mathrm{N}_{2}$. 


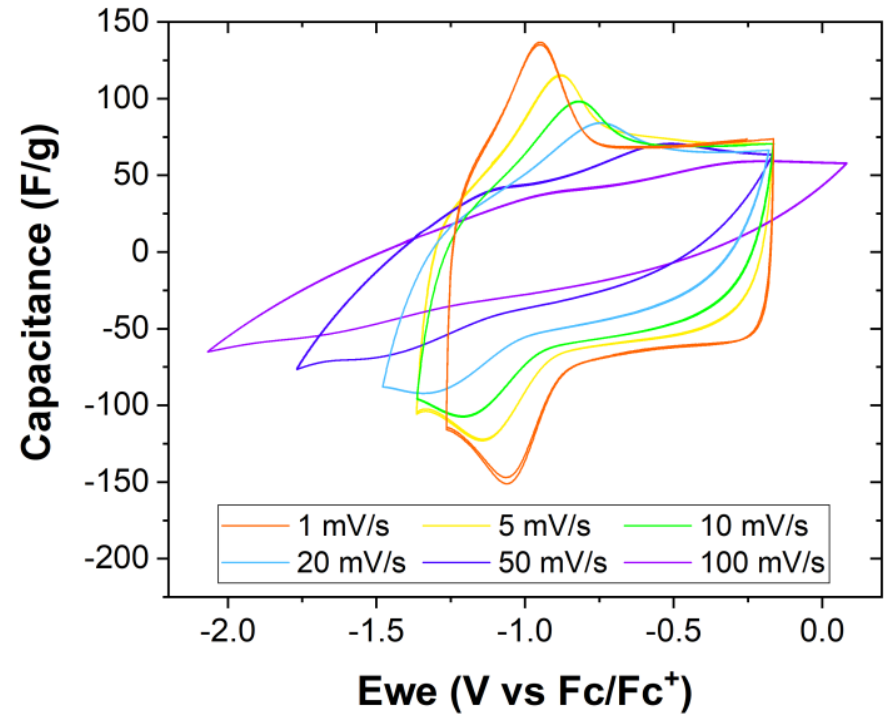

Figure S10. Cyclic voltammogram of GMA-PA- $\mathrm{C}_{60}$ at different potential sweep rates.

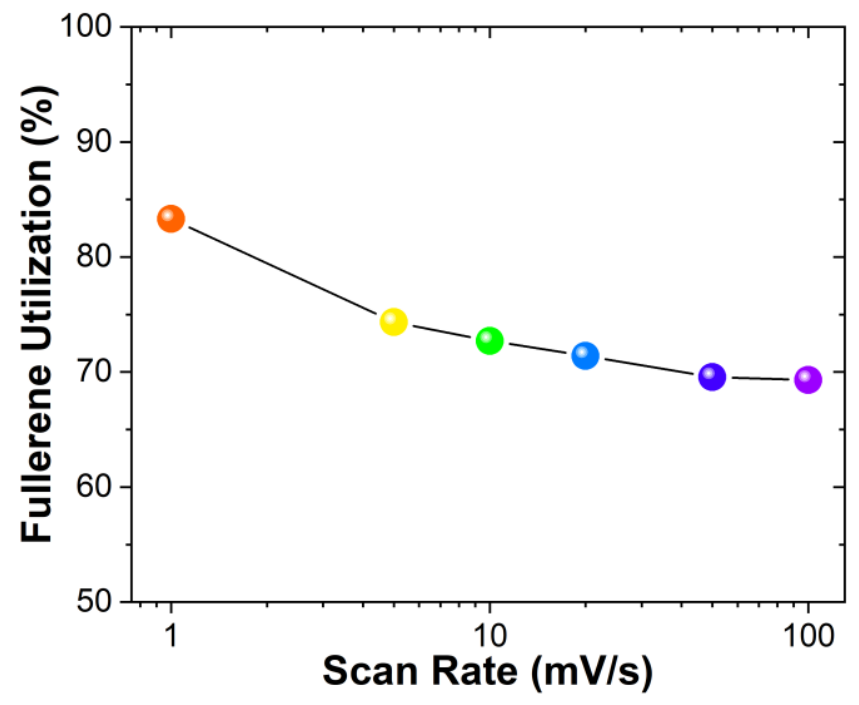

Figure S11. Percentage of fullerene utilization for GMA-PA- $\mathrm{C}_{60}$ as a function of scan rate. Values were derived by integrating the charge peak associated with PA-C 60 and subtracting the underlying area of GMA divided by the mass of fullerene physisorbed. 


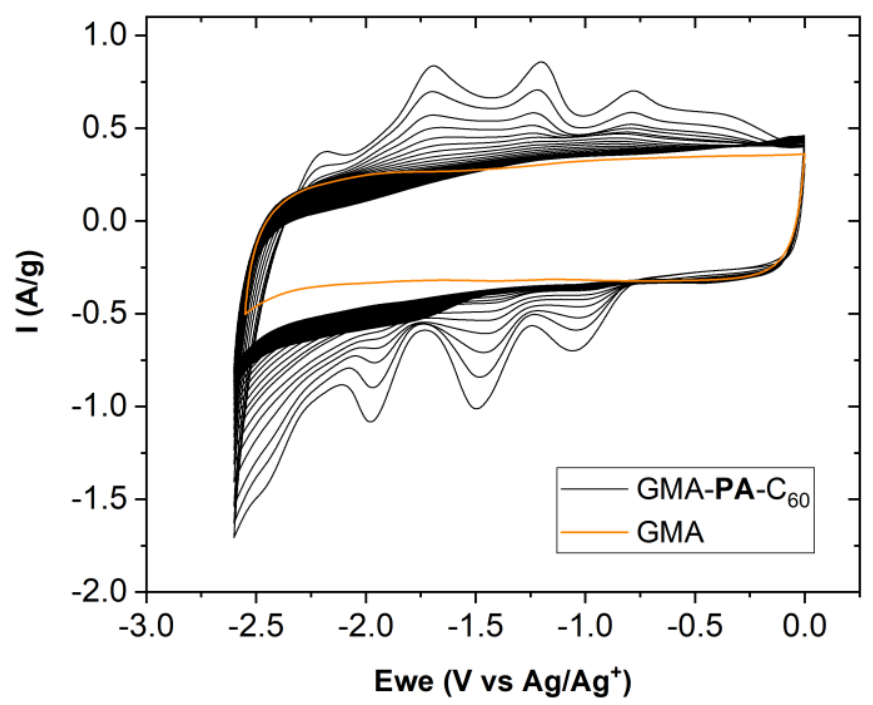

Figure S12. CV of GMA-PA-C 60,200 cycles from 0 to $-2.5 \mathrm{~V}, 34.45 \mathrm{wt} \%$ loading, scan rate 5 $\mathrm{mV} / \mathrm{s}, 0.1 \mathrm{M}$ TBAP in acetonitrile.

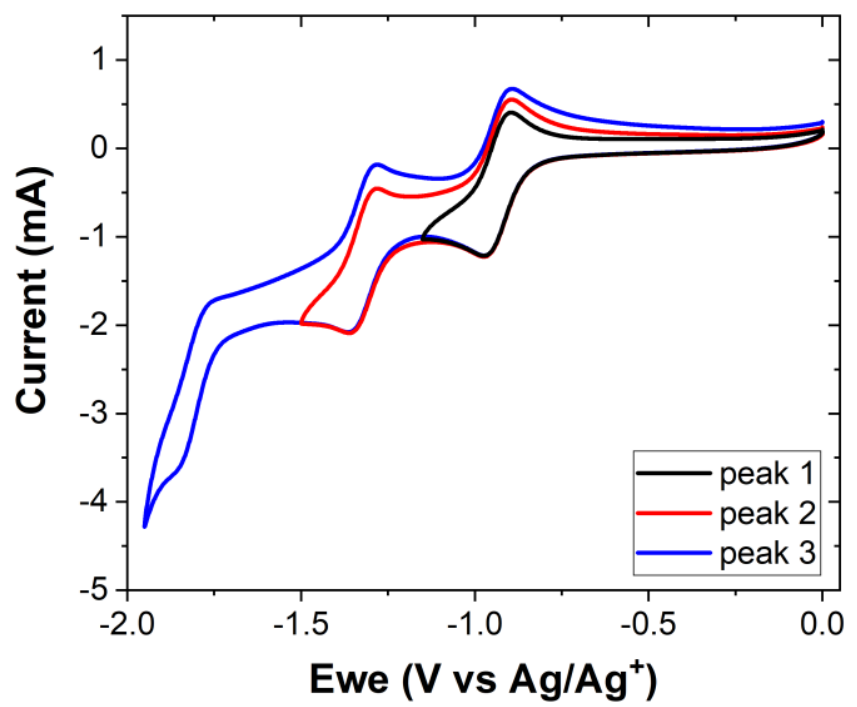

Figure S13. CV of three reduction peaks of $2.5 \mu \mathrm{M}$ PA- $\mathrm{C}_{60}$, scan rate $5 \mathrm{mV} / \mathrm{s}, 0.1 \mathrm{M}$ TBAP in dichloromethane. 


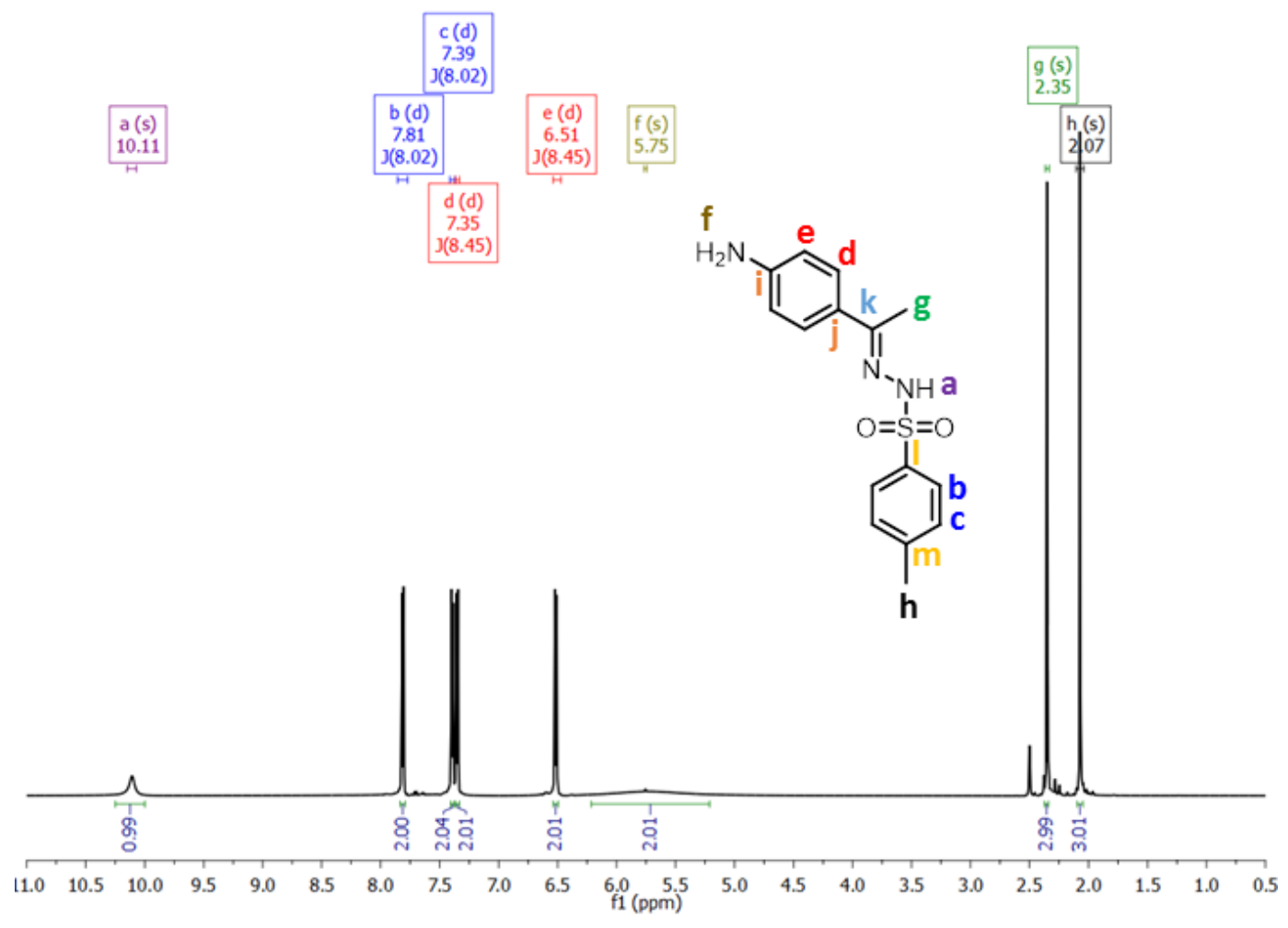

Figure S14. ${ }^{1} \mathrm{H}$ NMR (600 MHz; DMSO-d 6 , $298 \mathrm{~K}$ ); 1-(4-aminophenyl)ethano-p-toluenesulfonyl hydrazone: $\delta 10.11(\mathrm{~s}, 1 \mathrm{H},=\mathrm{N}-\mathrm{NH}), 7.81\left(\mathrm{~d}, 2 \mathrm{H}_{\mathrm{Ar}}, \mathrm{J}=8.02 \mathrm{~Hz}\right), 7.39\left(\mathrm{~d}, 2 \mathrm{H}_{\mathrm{Ar}}, \mathrm{J}=8.02 \mathrm{~Hz}\right), 7.35$ $\left(\mathrm{d}, 2 \mathrm{H}_{\mathrm{Ar}}, \mathrm{J}=8.45 \mathrm{~Hz}\right), 6.51\left(\mathrm{~d}, 2 \mathrm{H}_{\mathrm{Ar}}, \mathrm{J}=8.45 \mathrm{~Hz}\right), 5.75\left(\mathrm{~s}, 2 \mathrm{H},-\mathrm{NH}_{2}\right), 2.35\left(\mathrm{~s}, 3 \mathrm{H},-\mathrm{CH}_{3}\right), 2.07(\mathrm{~s}$, $\left.3 \mathrm{H},-\mathrm{CH}_{3}\right)$.

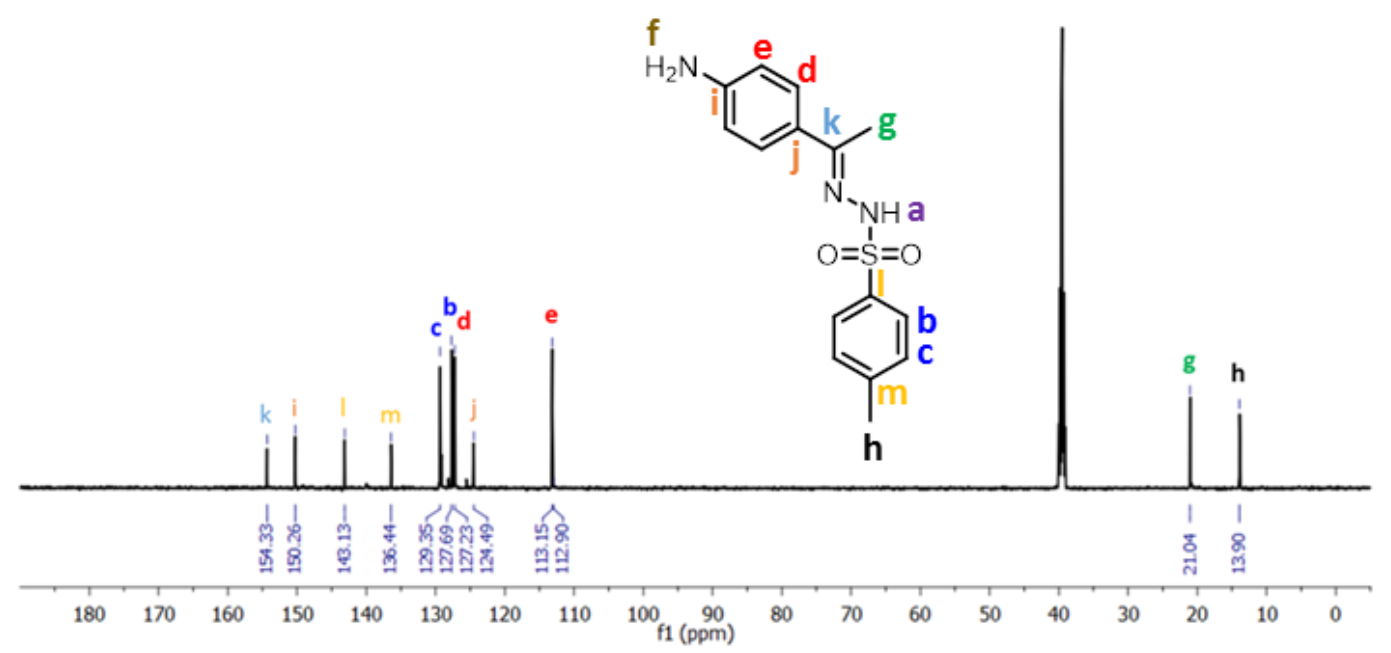

Figure S15. ${ }^{13} \mathrm{C}$ NMR (150 MHz; DMSO-d 6 , $298 \mathrm{~K}$ ); 1-(4-aminophenyl)ethano-p-toluenesulfonyl hydrazone: $\delta 154.33,150.26,143.13,136.44,129.35,127.69,127.23,124.49,113.15,112.90$, $21.04,13.90 \mathrm{ppm}$. 


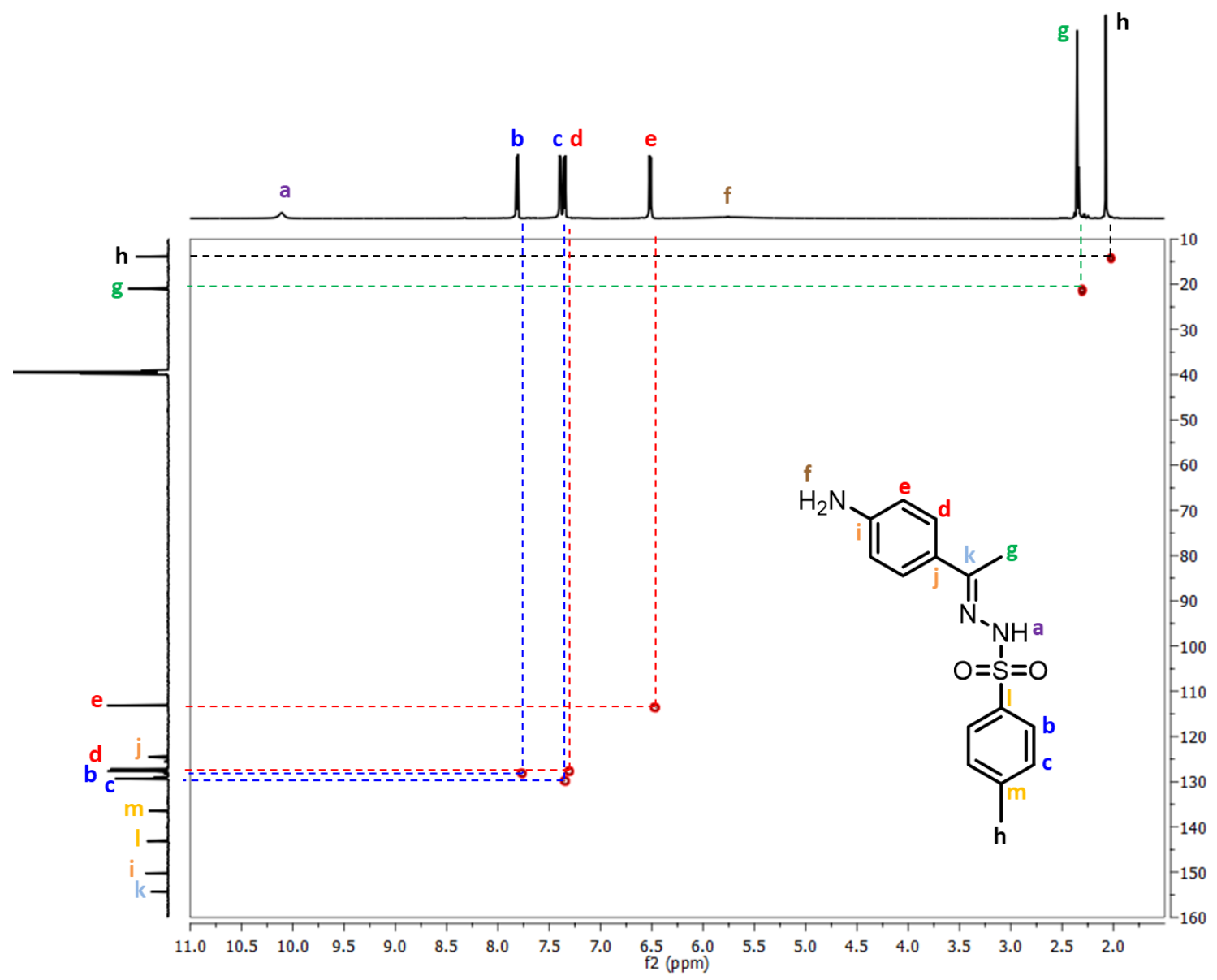

Figure S16. HMQC NMR (600 MHz; DMSO-d $6,298 \mathrm{~K})$ of 1-(4-aminophenyl)ethano-ptoluenesulfonyl hydrazone.

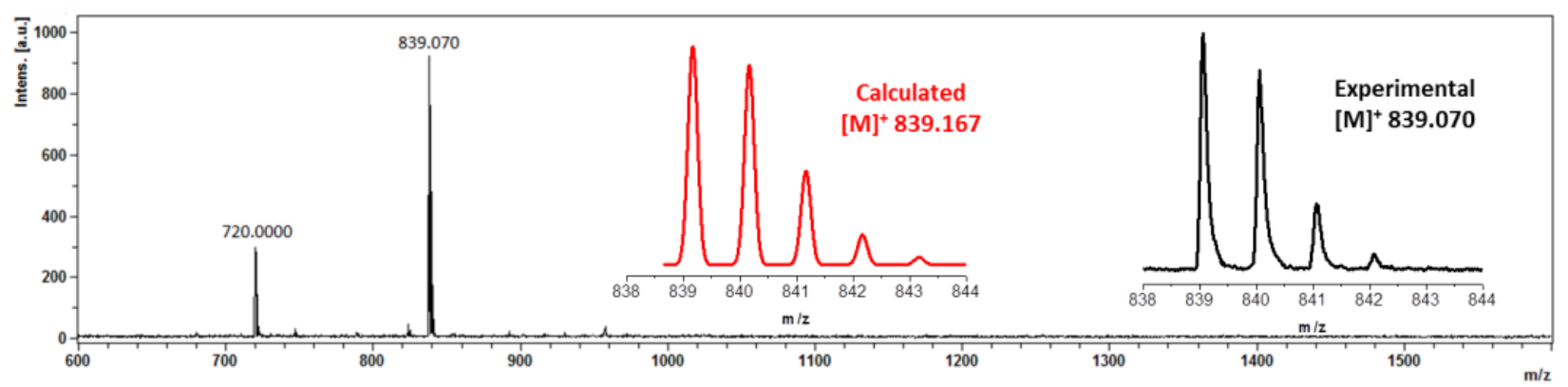

Figure S17. MALDI-TOF spectrum of PA-C 60 using TPB as a matrix. 


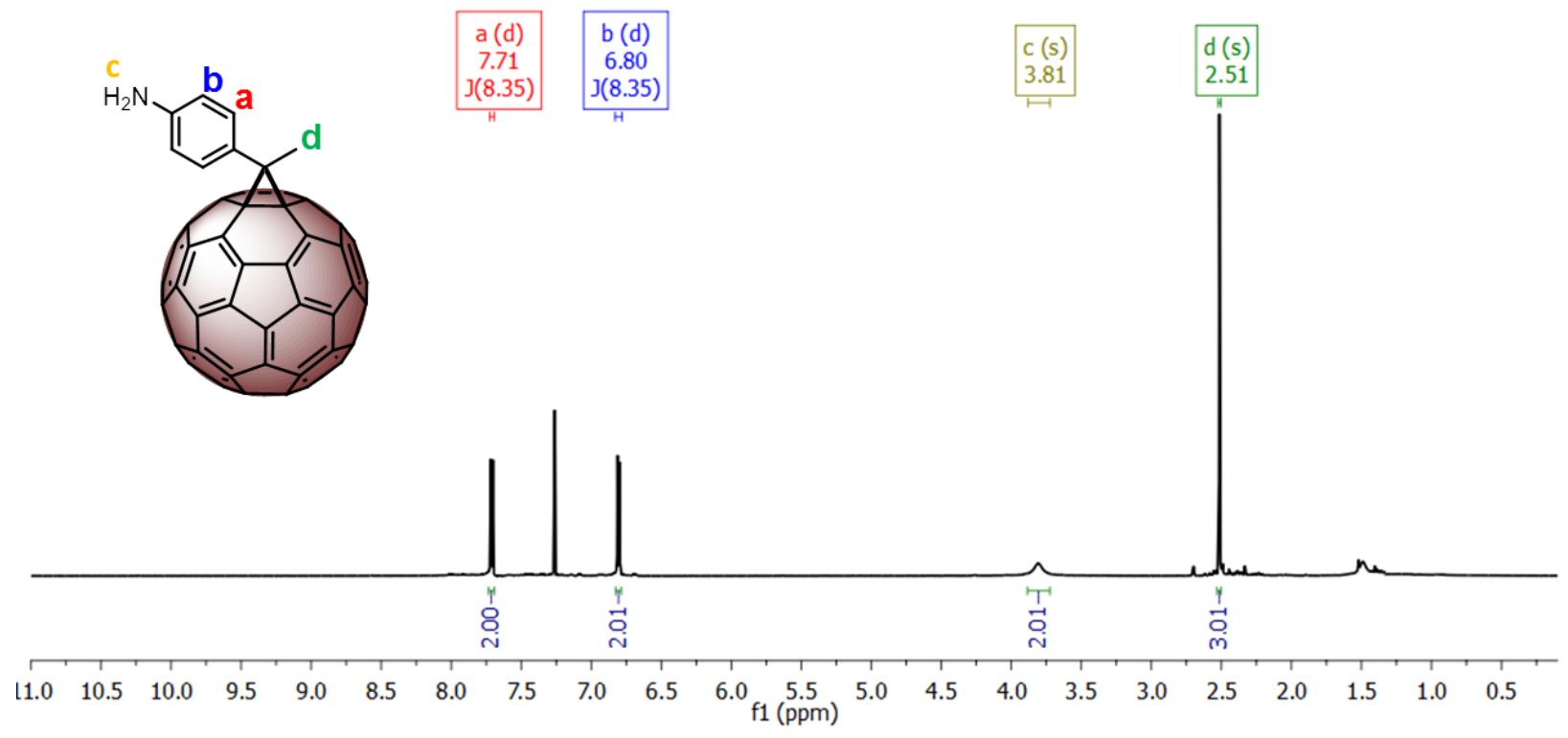

Figure S18. ${ }^{1} \mathrm{H}$ NMR (600 MHz; $\left.\mathrm{CDCl}_{3}: \mathrm{CS}_{2}(7 / 3), 298 \mathrm{~K}\right) ; \mathbf{P A}-\mathrm{C}_{60}: \delta 7.71\left(\mathrm{~d}, 2 \mathrm{H}_{\mathrm{Ar}}, \mathrm{J}=8.35 \mathrm{~Hz}\right)$, $6.80\left(\mathrm{~d}, 2 \mathrm{H}_{\mathrm{Ar}}, \mathrm{J}=8.35 \mathrm{~Hz}\right), 3.81\left(\mathrm{~s}, 2 \mathrm{H},-\mathrm{NH}_{2}\right), 2.51\left(\mathrm{~s}, 3 \mathrm{H},-\mathrm{CH}_{3}\right)$.

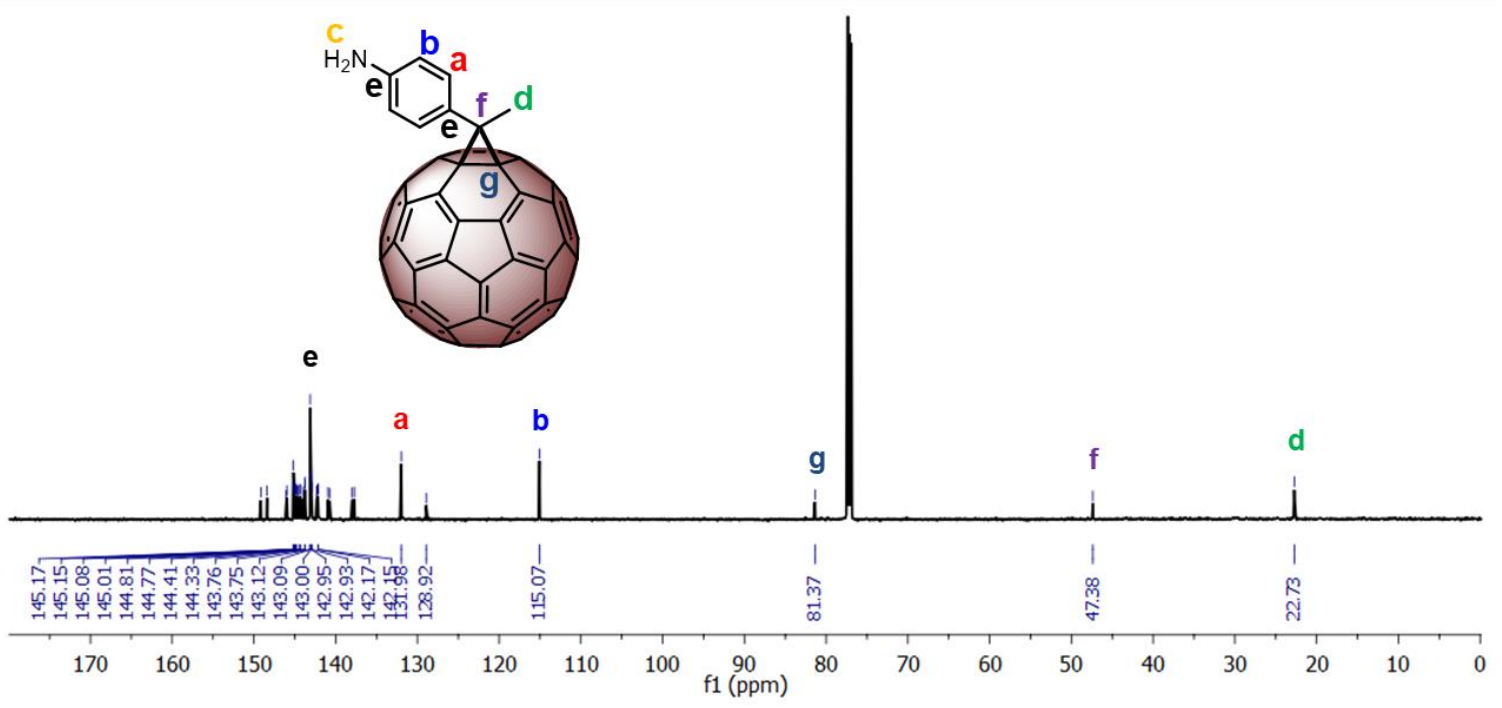

Figure S19. ${ }^{13} \mathrm{C}$ NMR number of signals $\left(150 \mathrm{MHz} ; \mathrm{CDCl}_{3}: \mathrm{CS}_{2}(7 / 3), 298 \mathrm{~K}\right) ; \mathbf{P A}-\mathrm{C}_{60}: \delta 145.17$, $145.15,145.08,145.01,144.81,144.77,144.41,144.33,143.76,143.75,143.12,143.09,143.00$, $142.95,142.93,142.17,142.15,131.98,128.92,115.07,81.37,47.38,22.73$ ppm. 


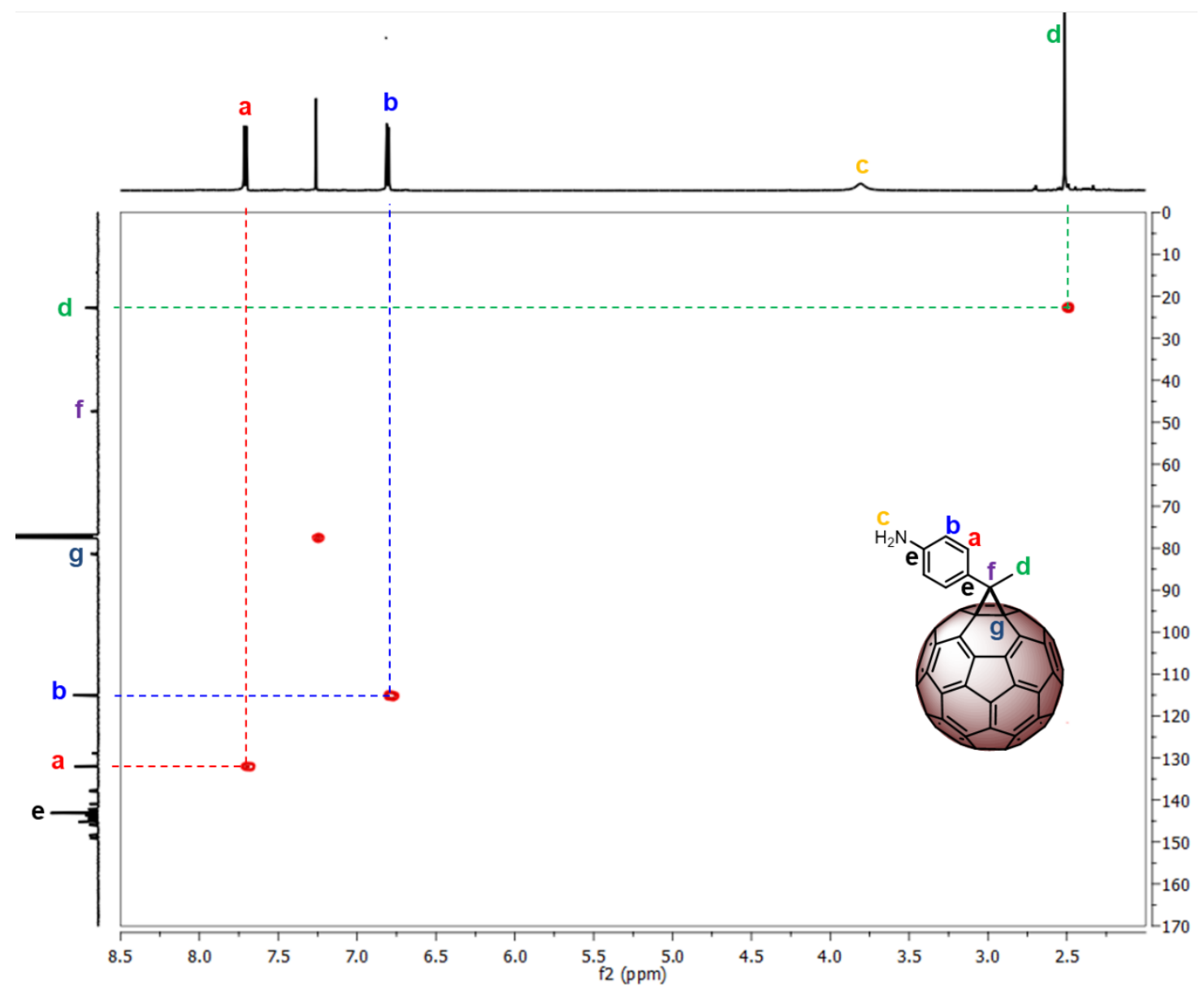

Figure S20. HMQC NMR (600 MHz; CDCl3/CS2 (7/3), 298 K) of PA-C 60.

${ }^{[1]}$ M. A. Worsley, S. O. Kucheyev, H. E. Mason, M. D. Merrill, B. P. Mayer, J. Lewicki, C. A. Valdez, M. E. Suss, M. Stadermann, P. J. Pauzauskie, J. H. Satcher, J. Biener, T. F. Baumann, Chem. Commun. 2012, 48, 8428.

${ }^{[2]}$ R. S. Ruoff, D. S. Tse, R. Malhotra and D. C. Lorents, J. Phys. Chem. 1993, 97, 3379.

${ }^{[3]}$ P. Zhang, J. Lu, Q. Xue and W. Liu, Langmuir 2001, 17, 2143.

${ }^{[4]}$ P. Giannozzi, S. Baroni, N. Bonini, M. Calandra, R. Car, C. Cavazzoni, D. Ceresoli, G. L. Chiarotti, M. Cococcioni, I. Dabo, J. Phys.: Condens. Matter 2009, 21, 395502.

${ }^{[5]}$ S. Plimpton, J. Comput. Phys. 1995, 117, 1-19.

${ }^{[6]}$ M. Neek-Amal, N. Abedpour, S. Rasuli, A. Naji, M. Ejtehadi, Phys. Rev. E 2010, 82, 051605.

${ }^{[7]}$ D. W. Brenner, Phys. Rev. B 1990, 42, 9458.

${ }^{[8]}$ H. Rafii-Tabar, Phys. Rep. 2004, 390, 235.

${ }^{[9]}$ X. Zhao, arXiv preprint arXiv:1209.4248 2012. 